\title{
Photodynamic Properties of Vital Dyes for Vitreoretinal Surgery
}

\author{
Tobias Brockmann $^{a}$ Claudia Steger ${ }^{a}$ Jens Dawczynski ${ }^{b}$ \\ ${ }^{a}$ Department of Ophthalmology, Charité - University Medicine Berlin, Berlin, and ${ }^{\mathrm{b}}$ Department of Ophthalmology \\ and Eye Hospital, Faculty of Medicine, University of Leipzig, Leipzig, Germany
}

\section{Key Words}

Indocyanine green • Brilliant blue G • Trypan blue •

Vital dye $\cdot$ Spectroscopy $\cdot$ Chromovitrectomy

\begin{abstract}
The purpose of this study was to evaluate photodynamic properties of indocyanine green (ICG), brilliant blue G (BBG) and trypan blue (TB) as currently used vital dyes for chromovitrectomy. Under consideration of intraoperative illumination intensities and dye concentrations, a simulative in vitro investigation was set up. Therefore, standardized dilutions of original ICG, BBG and TB vials were irradiated at a wavelength of $366 \mathrm{~nm}$ with an intensity of $14 \mu \mathrm{W} / \mathrm{cm}^{2}$ between 0 and $48 \mathrm{~h}$. After this, all samples were measured spectroscopically in a 220- to 750-nm bandwidth. Analyzing the vital dyes over the time course, an exponential photolysis was observed for ICG, whereas BBG and TB presented photostable properties. Regarding ICG, $5 \%$ of the concentration was degraded to toxic metabolites every $20 \mathrm{~min}$. For this reason, our study provides evidence that intraocular dye concentrations and modern endoillumination systems alone cannot fully prevent ICG photodegradation.
\end{abstract}

Copyright $\odot 2012$ S. Karger AG, Basel
(C) 2012 S. Karger AG, Basel

$0030-3755 / 12 / 2284-0234 \$ 38.00 / 0$

Fax +4161306 1234

E-Mail karger@karger.ch

www.karger.com
Accessible online at:

www.karger.com/oph

\section{Introduction}

Over the last decade, the intravitreal application of vital dyes in macular surgery has become an integral part of the internal limiting membrane (ILM) and epiretinal membrane peeling [1]. Indocyanine green (ICG), brilliant blue $\mathrm{G}(\mathrm{BBG})$ and trypan blue (TB) are the currently used dyes for chromovitrectomy. Whereas ICG and BBG have a high affinity to the ILM [2], TB is highly receptive to the epiretinal membrane [3]. Ever since the introduction of membrane staining, an ongoing debate about the safety of vital dye has emerged. In particular ICG is supposed to have a dose- and illumination-dependent toxicity in retinal ganglion cells and the retinal pigment epithelium, even in clinically used concentrations [4-6]. On this occasion, several measures were taken to improve the safety profile. On the one hand, modifications of the chemical composition such as adding glucose or eliminating free iodine (infracyanine green) were introduced [7-9]. On the other hand, the surgical illumination was adapted to the absorption spectrum by inserting long-pass filters [10].

Accordingly, the purpose of this study was to investigate photodynamic properties of ICG, BBG and TB taking intravitreous dye concentrations and intraoperative light intensities into account. 
Fig. 1. Spectrophotometric characteristics of ICG, BBG and TB solutions in aqua bidest. Major peaks are highlighted with a marking line at $580 \mathrm{~nm}$ (BBG), $590 \mathrm{~nm}$ (TB) and $700 \mathrm{~nm}$ (ICG).
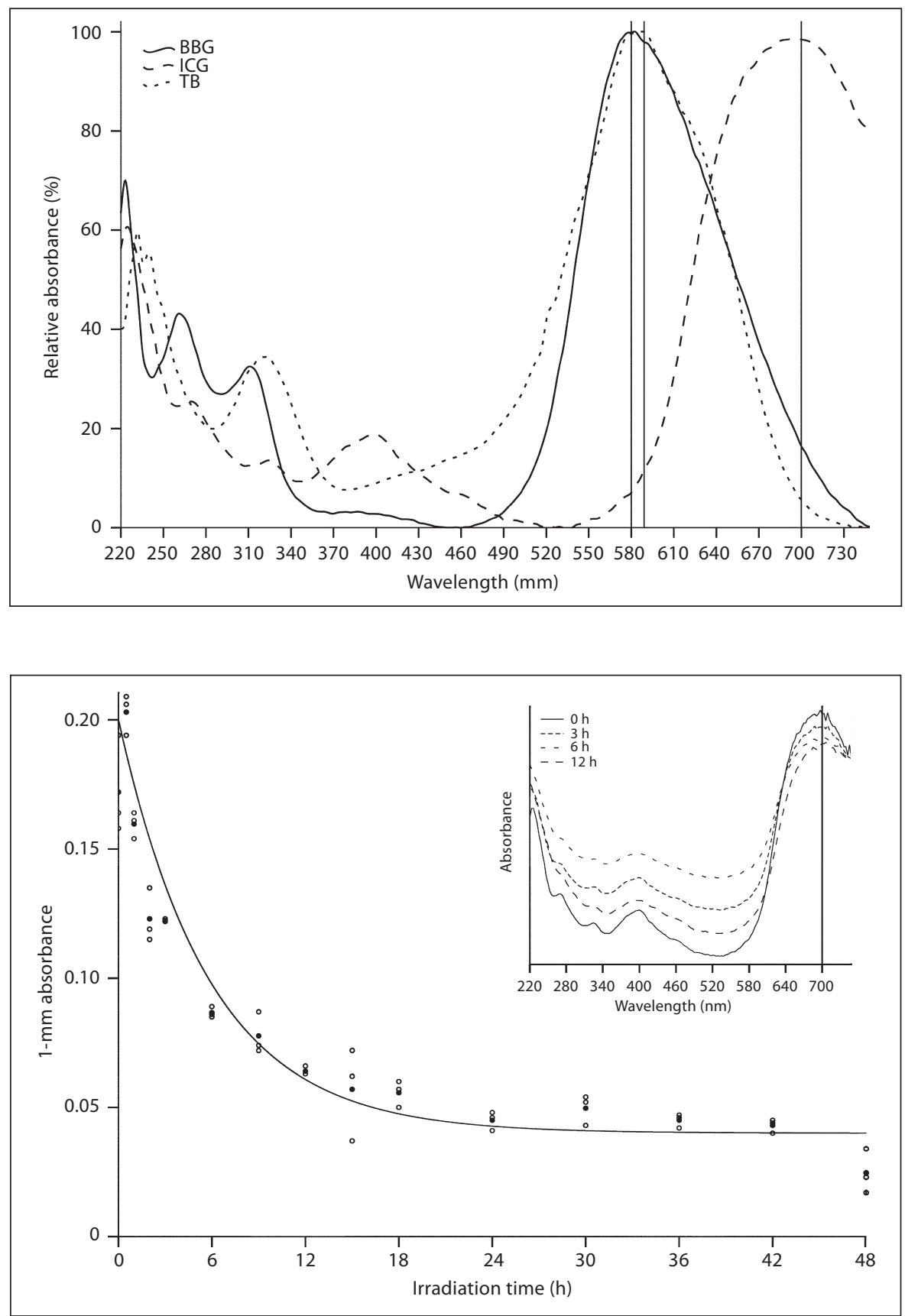

Fig. 2. ICG demonstrates an exponential decrease of absorbance at a wavelength of $700 \mathrm{~nm}$ during 48-hour illumination. Spectrophotometric changes in respect to the illumination time are illustrated in the bandwidth of 220-750 $\mathrm{nm}$. The variability of the spectra $\leq 600 \mathrm{~nm}$ might be explained by sensitive changes of light emission caused by photoreactive metabolites. and $0.3 \mathrm{mg} / \mathrm{ml}$, and TB was diluted $1: 50$ to $0.003 \mathrm{mg} / \mathrm{ml} .20 \mathrm{mi}-$ croliters aliquots of each dye were filled into 15 borosilicate capillaries (GB 150 F-10; Hilgenberg, Malsfeld, Germany) and sealed to avoid evaporation.

Subsequently, the samples were irradiated by a mercury-vapor lamp with an intensity of $14 \mu \mathrm{W} / \mathrm{cm}^{2}$ at a wavelength of $366 \mathrm{~nm}(6$ KLU; Neolab, Heidelberg, Germany). In consideration of $90 \%$ transmission rate of borosilicate glass at $366 \mathrm{~nm}$, an effective irradiation intensity of $12.6 \mu \mathrm{W} / \mathrm{cm}^{2}$ was induced. To investigate grad- 


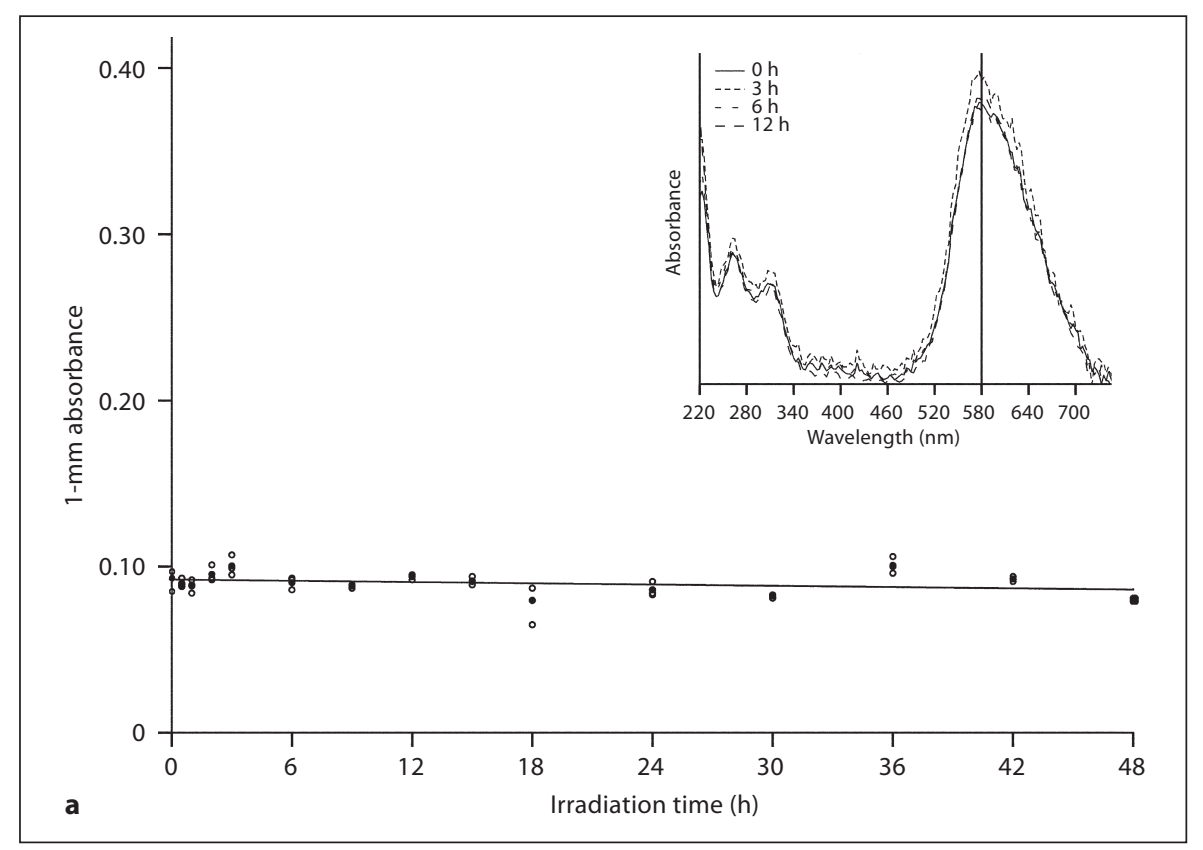

Fig. 3. Stable spectrophotometric properties were observed for blue dyes during 48-hour illumination in the bandwidth of 220-750 nm. a The absorbance of BBG at $580 \mathrm{~nm}$ remains constant. b For TB, comparable photostable properties were found, whereby the molar absorbance was higher in respect to $\mathrm{BBG}$.

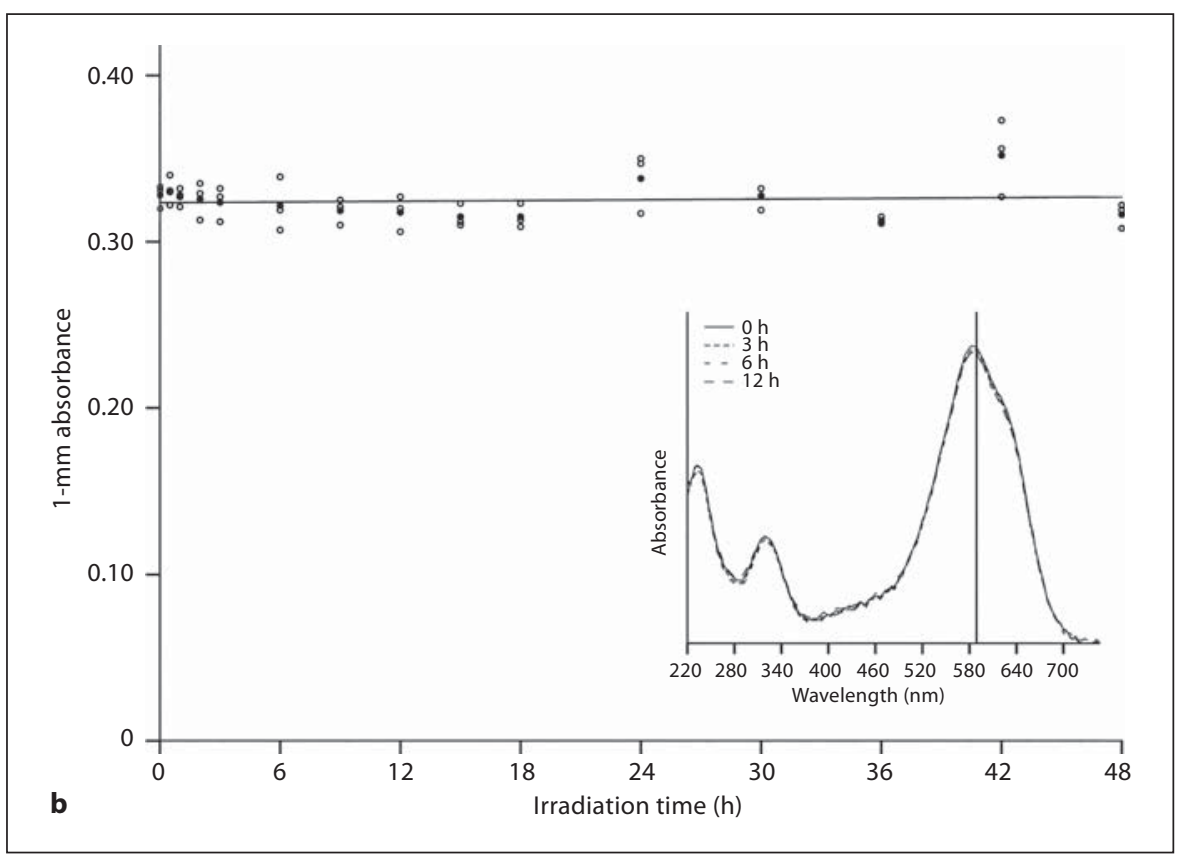

ual and delayed light-induced conformational changes, the irradiation time ranged from 0.5 to $48 \mathrm{~h}(0.5,1,2,3,6,9,12,15,18,24$, $30,36,42$ and $48 \mathrm{~h}$ ). After predefined irradiation periods the samples were stored at $4^{\circ} \mathrm{C}$ protected from light. One sample of each dye without irradiation served as a control. Following this, all samples were measured 3 times spectroscopically at a bandwidth of 220-750 nm using NanoDrop 1000 spectrophotometer (Thermo Fisher Scientific, Wilmington, Mass., USA). Spectroscopic curves were digitized with NanoDrop 1000 software version 3.7.1 and an- alyzed with SPSS version 19.0 (SPSS Inc., Chicago, Ill., USA). To evaluate the relevance of our findings, the Beer-Lambert law $(E \lambda=\varepsilon \lambda \cdot c \cdot d, E \lambda=$ absorbance, $\varepsilon \lambda=$ molar absorptivity, $c=$ concentration and $d=$ thickness of the substance) had to be considered. Corresponding to our investigation, we accepted the molar absorptivity and a 1-mm thickness as given, so that the influenced variable was the concentration. 


\section{Results}

Dye solutions without irradiation served as controls and demonstrated specific absorption spectra within the bandwidth of 220-750 nm, as shown in figure 1. ICG (1.0 $\mathrm{mg} / \mathrm{ml}$ ) produces a major $700-\mathrm{nm}$ and a minor $400-\mathrm{nm}$ peak. BBG $(0.3 \mathrm{mg} / \mathrm{ml})$ represents a major $580-\mathrm{nm}$ and two minor peaks at 260 and $310 \mathrm{~nm}$. TB $(0.003 \mathrm{mg} / \mathrm{ml})$ shows a major 590-nm and a minor 325-nm peak (see also online suppl. tables; for all online suppl. material, see www.karger.com/doi/10.1159/000341605).

To evaluate the effects of 366-nm irradiation on the vital dyes, major absorption peaks were analyzed. For ICG, an exponential decrease of absorbance was found with a dynamic phase from 0 to $24 \mathrm{~h}$ followed by a static phase as illustrated in figure 2 . As an approximation, the absorption of ICG at $700 \mathrm{~nm}$ declines over time ( $t$ in hours) by $E_{\text {ICG700 }}=0.04+0.16^{-0.17 t}$. In contrast, no significant spectroscopic changes were observed for either BBG or TB during irradiation, as shown in figure 3 . Thus, we found a constant concentration during the irradiation of $\mathrm{BBG}$ and $\mathrm{TB}$, whereas the concentration ( $c_{I C G}$ in percent) of ICG declined over time ( $t$ in hours) by $c_{I C G}=100^{-0.17 t}$. The amount of decomposed ICG in the course of 1-hour light exposure is demonstrated in table 1 ; accordingly more than $5 \%$ were degraded after $20 \mathrm{~min}$.

\section{Conclusions}

The experimental setup of our study was planned to emulate intraoperative illumination and dye concentrations for the evaluation of photodynamic characteristics.

Previous comparisons of established 20-gauge endoillumination systems disclosed intensities between 23 and $285 \mathrm{~mW} / \mathrm{cm}^{2}$ within a $10-\mathrm{mm}$ retina distance [11]. Therefore, we considered an average intensity of $\sim 130 \mathrm{~mW} / \mathrm{cm}^{2}$ for our investigations. Especially light of a wavelength of less than $475 \mathrm{~nm}$ is known to degrade light-absorbing molecules. Although common illuminants such as halogen, mercury vapor, xenon or metal halide excite different emission spectra, about $1 / 10$ of the intensity is represented in a bandwidth of less than $475 \mathrm{~nm}$. To minimize energetic light, 475-nm long-pass optical filters were introduced to endoillumination systems [12]. Leading manufacturers state a transmission rate of $0.1 \%$ for optical filters. Taking the technical features into consideration, an actual intraoperative intensity of $13 \mu \mathrm{W} / \mathrm{cm}^{2}$ is attained for light of a wavelength of less than $475 \mathrm{~nm}$.
Table 1. Changes of ICG absorbance and the proportion of photolytic metabolites during 1-hour illumination

\begin{tabular}{rll}
\hline Time, min & Absorbance at $700 \mathrm{~nm}$ & Degraded proportion, \% \\
\hline 0 & 0.200 & 0.0 \\
5 & 0.198 & 1.4 \\
10 & 0.196 & 2.8 \\
15 & 0.193 & 4.2 \\
20 & 0.191 & 5.5 \\
25 & 0.189 & 6.8 \\
30 & 0.187 & 8.1 \\
35 & 0.185 & 9.4 \\
40 & 0.183 & 10.7 \\
45 & 0.181 & 12.0 \\
50 & 0.179 & 13.2 \\
55 & 0.177 & 14.4 \\
60 & 0.175 & 15.6 \\
\hline
\end{tabular}

Correspondingly, we applied an effective intensity of 12.6 $\mu \mathrm{W} / \mathrm{cm}^{2}$.

Intraoperative measurements of intraocular ICG concentrations during macular hole surgery revealed a dilution factor of 1:50 [13]. Since ICG and BBG have a high affinity to the ILM, where potential neuroretinal damage might be induced, we considered a 10 times higher concentration within the ILM. Whereas TB adheres to epiretinal membrane and rarely accumulates on the ILM, a dilution factor of 1:50 was retained.

Our findings demonstrated vast photodynamic characteristics of ICG in contrast to BBG and TB. While the toxicity of BBG and TB is being discussed [14], a photodynamic effect and the formation of toxic metabolites should be revoked. Indeed, we observed a degradation of ICG in clinical settings which trigger toxic metabolites to a remarkable extent [15]. During illumination, more than 5\% ICG are transformed every $20 \mathrm{~min}$. These findings might also clarify ultrastructural alterations of the ILM after dye-assisted membrane peeling. A shrinkage and stiffening of the ILM was observed after ICG application, which resulted in an enhanced separation of the ILM from the adjacent neuroretina [16]. In this account the present findings confirm the hypothesis that ICG is being photodegraded under intraoperative conditions and might potentially induce a collagen cross-linkage on the ILM.

Nevertheless, we are aware that our investigation has several limitations, especially because of its in vitro design to estimate realistic intraoperative circumstances. During a 48-hour irradiation, the lamp heats up and the 
excitation intensity decreases. In addition, lower light intensities are also present in 23-gauge endoillumination systems. Even though, the dye concentrations were based on intraoperative investigations, we determined relative proportions so that actual concentrations are considered negligible.
On this account, this study provides evidence that intraocular concentrations and intraoperative illumination intensities under consideration of 475-nm long-pass optical filters alone cannot prevent significant photodegradation of ICG, while BBG and TB did not present an accordant photosensitivity.

\section{References}

$>1$ Farah ME, Maia M, Rodrigues EB: Dyes in ocular surgery: principles for use in chromovitrectomy. Am J Ophthalmol 2009;148:332340.

$\checkmark 2$ Mennel S, Meyer CH, Schmidt JC, Kaempf S, Thumann G: Trityl dyes patent blue $\mathrm{v}$ and brilliant blue $\mathrm{G}$ - clinical relevance and in vitro analysis of the function of the outer blood-retinal barrier. Dev Ophthalmol 2008; 42:101-114.

3 Kwok AK, Lai TY, Li WW, Yew DT, Wong VW: Trypan blue- and indocyanine greenassisted epiretinal membrane surgery: clinical and histopathological studies. Eye (Lond) 2004; 18:882-888.

$\checkmark 4$ Balaiya S, Brar VS, Murthy RK, Chalam KV: Comparative in vitro safety analysis of dyes for chromovitrectomy: indocyanine green, brilliant blue green, bromophenol blue, and infracyanine green. Retina 2011;31:11281136.

$>5$ Rodrigues EB, Meyer CH, Mennel S, Farah ME: Mechanisms of intravitreal toxicity of indocyanine green dye: implications for chromovitrectomy. Retina 2007;27:958-970.

6 Stanescu-Segall D, Jackson TL: Vital staining with indocyanine green: a review of the clinical and experimental studies relating to safety. Eye (Lond) 2009;23:504-518.
7 Rizzo S, Belting C, Genovesi-Ebert F, Vento A, Cresti F: Modified technique for safer indocyanine-green-assisted peeling of the internal limiting membrane during vitrectomy for macular hole repair. Graefes Arch Clin Exp Ophthalmol 2006;244:1615-1619.

$>8$ Jackson TL, Vote B, Knight BC, El-Amir A, Stanford MR, Marshall J: Safety testing of infracyanine green using retinal pigment epithelium and glial cell cultures. Invest Ophthalmol Vis Sci 2004;45:3697-3703.

$\checkmark 9$ Haritoglou C, Gandorfer A, Gass CA, Kampik A: Histology of the vitreoretinal interface after staining of the internal limiting membrane using glucose 5\% diluted indocyanine and infracyanine green. Am J Ophthalmol 2004;137:345-348.

10 van den Biesen PR, Berenschot T, Verdaasdonk RM, van Weelden $H$, van Norren $D$ : Endoillumination during vitrectomy and phototoxicity thresholds. Br J Ophthalmol 2000;84:1372-1375.

11 Ach T, Höh AE, Amberger R, Dithmar S: Exposure to light during vitreoretinal surgery. II. Characteristics of endoilluminators (in German). Ophthalmologe 2008;105:905910.
12 Hillenkamp J, Dydykina S, Klettner A, Treumer F, Vasold R, Bäumler W, Roider J: Safety testing of indocyanine green with different surgical light sources and the protective effect of optical filters. Retina 2010;30: 1685-1691.

13 Ohguro H, Ohguro I, Ishikawa F, Hitoshi Y, Yokoi Y, Nakazawa M: Changes in intraocular indocyanine green concentrations during macular hole surgery. Ophthalmologica 2007;221:402-405.

14 Morales MC, Freire V, Asumendi A, Araiz J, Herrera I, Castiella G, Corcóstegui I, Corcóstegui G: Comparative effects of six intraocular vital dyes on retinal pigment epithelial cells. Invest Ophthalmol Vis Sci 2010;51: 6018-6029.

15 Engel E, Schraml R, Maisch T, Kobuch K, König B, Szeimies RM, Hillenkamp J, Bäumler W, Vasold R: Light-induced decomposition of indocyanine green. Invest Ophthalmol Vis Sci 2008;49:1777-1783.

16 Brockmann T, Steger C, Westermann M, Nietzsche S, Koenigsdoerffer E, Strobel J, Dawczynski J: Ultrastructure of the membrana limitans interna after dye-assisted membrane peeling. Ophthalmologica 2011; 226:228-233. 